\title{
COM \\ Time to teach post-normal science communication? Fostering the engagement of the extended peer community in an academic course of Environmental Sciences
}

\section{Alba L'Astorina, Alessia Ghezzi, Stefano Guerzoni and Emanuela Molinaroli}

Abstract

In November 2016, within an Environmental studies course at the University of Venice, students carried out an experiment aimed at collecting scenarios of the Venetian coast's future starting from lessons learnt during the episode of storm surge 50 years ago (Aqua Granda flood).

The students built scenarios able to anticipate the effect of sea level rise on coastal areas in Venice, based not only on scientific input but also on a methodology called "Futurescape city Tours" (FCT) involving inhabitants of the barrier islands of Lido and Pellestrina.

This paper will explore three main questions: (i) Can participatory and experiential methodologies, such as FCT help students behave in an anticipatory and inclusive way in their future professional activities? (ii) Can we talk about post-normal science teaching? - i.e. one that acknowledges and works with science and other knowledges to address societal issues?

(iii) Can such an approach challenge students thinking in relation to knowledge hierarchies?

Keywords

DOI

Environmental communication; Informal learning; Public engagement with science and technology

https://doi.org/10.22323/2.17040802

Introduction

\begin{abstract}
"On November $4^{\text {th }}, 1966$, the city of Venice woke up in the middle of its biggest nightmare. The largest flood in its history reached a level of $194 \mathrm{~cm}$ above median sea level and covered almost the entire city. The tide remained for 22 hours above $110 \mathrm{~cm}$ and for about 40 hours over $50 \mathrm{~cm}$. It created a lot of damage in the historical centre and on the lagoon islands." (Aqua Granda: the story of an eventful day in Venice, https://www.theveniceinsider.com/acqua-granda-flood-venice/)
\end{abstract}

Flooding in Venice is not new. High tides have been invading the city since the $6^{\text {th }}$ century and people have always co-existed with the sea and created and adopted numerous interventions to adapt to flooding and the aqueous milieu. Pellestrina is 
one of the two long and thin barrier islands (the other being the Lido) where in the $18^{\text {th }}$ century a long stonewall, Murazzi, ${ }^{1}$ was built to protect the city from the sea.

In 1966, the Aqua Granda destroyed part of this defence; thousands of residents were left without homes and an entire local farming based economy was destroyed. Several adaptation measures were put in place in Venice to counteract the flooding events, after 1966. They can be subdivided in widespread interventions and the barrier system, first proposed in 1981 and funded through the Special Law nr. 789 of 1984. In addition, the city is constantly confronted with the problem of acqua alta, i.e. flooding that occurs mainly during the winter as a result of convergence of high-tides and a strong southern Sirocco wind. Apart from the "normal" high water during the last 20 years, nine "exceptional" events $(>140 \mathrm{~cm})$ have occurred, during which $\sim 90 \%$ of the city surface and more than half of the public space dedicated to pedestrian use were inundated. The resulting consequences for people, economic activities, and buildings were considerable.

After the Aqua Granda event, the approach to face this risk has mainly been technocratic, in the sense that it has been handled by experts and bureaucrats. Many of the solutions explored had little consideration of situated uncertainties and complexities of Venice. For example, the lagoon, the barriers, the sea and the underground waters form a unique environmental complex ecosystem in which public participation and area-based management has often been neglected by administrative bodies involved in the planning of coastal projects and public works [Suman, Guerzoni and Molinaroli, 2005]. An example of this is the story of the construction of flood protection barriers (the famous MOSE, ${ }^{2}$ see also Nosengo [2003]), a contested decision taken more than 25 years ago by the Italian government, overlooking expert advice, namely regarding uncertainty due to climate change effects on sea-level rise and on ecosystems. The maintenance of the Murazzi, after a first reconstruction after the flood ('90s) is no longer carried out putting people living in the "barrier islands" in a highly vulnerable situation.

The project we present in this paper (Futuring Venice 2056) took place in November 2016 , on the occasion of the $50^{\text {th }}$ year anniversary of the dramatic high water (Aqua Granda flood) in Venice, involving students from the Environmental Science degree within the course "Geomorphology and sedimentology of coastal systems" in Venice. The general aim of the academic course is to provide the knowledge and methodological basis necessary for the analysis, evaluation and management of environmental systems, both natural and modified by humans. In particular, students should acquire knowledge and understanding of factors, processes and morphological characteristics that determine the behaviour of coastal sedimentary systems, together with vulnerability and environmental changes caused by human activities.

This project aimed at bringing, in some way, the students' attention to the episode of the Aqua Granda and thus linking the course itself to the current high water events (around 10\% of the city is flooded 15-20 times a year) and to the risk of coastal flooding, partially due to sea level rise. The background information used

\footnotetext{
${ }^{1}$ Murazzi: seawalls made of Istrian stone, built in 1789 by the Republic of Venice to defend the banks of the lagoon from the erosion of the sea.

${ }^{2}$ MOSE: a storm surge barrier that could close the lagoon of Venice during high flood $($ at $110 \mathrm{~cm}$ above sea level) in the Adriatic. Construction started in 2003 and should be completed in 2021.
} 
was the increase in the frequency of high water episodes over the last 50 years and the different estimates of sea level rise over the next 50 years. All the students of the course were thus involved in a public engagement activity - based on an experiential and sensorial approach - aimed at creating inclusive and participatory scenarios on the evolution of the coastal area of Venice starting from lesson learnt during Aqua Alta. In particular, the focus was on the barrier islands of Lido and Pellestrina, where the storm destroyed part of the Murazzi and caused major damage.

Background and methodologies
In the late 1990's a project called VISIONS ${ }^{3}$ [see Guimarães Pereira and Funtowicz, 2013] developed activities related to imagining futures for Venice; these were conceived as a "collective exercise" which engaged an extended peer community to provide "extended facts". ${ }^{4}$ This project was rooted on Post Normal Science (PNS) insights, which suggest that for some types of complex societal issues we need to mobilise all types of knowledge and perspectives besides scientific knowledge. A PNS approach is particularly necessary when 'facts are uncertain, values in dispute, stakes are high and decisions urgent' [Funtowicz and Ravetz, 1991, p. 138]. In these cases, the quality (fitness for purpose or function) of a decision making process cannot only rely on "experts" knowledge but requires the participation of an "extended peer community", including all those with a stake in the relevant problem. The framework encourages methodological approaches that design participatory spaces to engage different actors in co-creating futures and deliberating about them. The VISIONS project has been a sort of departing point for the work that is now presented here. In other words, the authors want to further the idea of "collective exercise" by exploring how university education of future planners could lead to institutional and social change when it comes to imagine or plan city futures - in this case.

There are many projects that explore how learning processes in universities are connected to social change [Barth et al., 2014; Nazir and Pedretti, 2015]. We are especially interested in those that engage university students - who could become future decision-makers - learn to deal with societal challenges and uncertainties in a practical way. Such projects are meant to develop in students an understanding for "wicked" sustainability problems (i.e. problems that are hard to address because of inexistent or incomplete knowledge, such as climate change), learn about approaches for solving them and eventually become change agents for a more sustainable society in the future [Schneidewind et al., 2016]. For example, "Farming the future" [Alvarez and Rogers, 2006] is structured around a four day field trip, organised around a particular theme such as water, climate change or the urban fringe. Emphasis is placed on the complexity of defining the term "sustainability". During the field trip students are introduced to a local "issue" or "issues" through conversations with community members, thus providing the students with an opportunity to listen to, identify and engage with a diversity of view-points, critically reflecting on how their understanding of sustainability and of community have been transformed as a result of such conversations.

\footnotetext{
${ }^{3}$ Visions of Sustainability for Europe, funded by the European Commission.

4 "Extended facts" may include craft wisdom and community knowledge of places and their histories, as well as anecdotal evidence, neighbourhood surveys, investigative journalism and leaked documents." [Funtowicz and Ravetz, 2003].
} 
Experiences of "walking and noticing" and of "outdoor learning" based on the idea that "learning should never occur as isolated events in a classroom rather through the process of bodily moving across spaces, time and places" [Gray and Colucci-Gray, 2018, accepted/in press] offer hints to re-conceptualise aims and practices of traditional academic education in order to respond to societal challenges, and to bring forth a sustainability view. These experiences foster the development in students of an "ecological identity", defined as the 'sense of self as part of an ecosystem' [Clayton and Opotow, 2003]. Introducing an approach where scientific knowledge is presented as a performative and dynamic process, aims at developing in students "a response-able" attitude to the "complex, unplanned and emergent" [Haraway cited in Colucci-Gray, 2018] in their future personal and professional life.

More generally, science communication projects in schools [see e.g. L'Astorina and Valente, 2011] benefit from participatory approaches that seek to involve many actors - teachers, students, experts, stakeholders and authorities - because they allow that a debate of controversial environmental issues goes beyond mere scientific facts. For example, participatory methodologies in educational settings can help with reflecting on the role of the teacher who, besides acting as a facilitator, may reflect on his/her practice, becoming what Lisle [2000] described a "reflexive practitioner" [Lisle, 2000].

\section{"Futurescape City Tours"}

In an effort to create a more inclusive, sustainable, and integrated public engagement experience, researchers at the Center for Nanotechnology in Society at Arizona State University (CNS-ASU) developed Futurescape City Tours (FCTs). The methodology proposes a participatory approach, based on "material deliberation" that consists of spatio-visual engagement with the urban landscape starting from noticing the city and its transition elements and aimed at collectively deliberating prospects for the future. Combining a walking tour, photography, guided deliberation, behind-the-scenes expeditions, and informal conversations with city planners, policymakers, researchers, and civic leaders, FCTs attempt to embed citizens' values into local systems of innovation [Davies et al., 2013; Selin and Pillen Banks, 2014].

This versatile methodology has been applied in North America and Europe, being adapted to different contexts besides city development and planning; for example in the "Food Futuring Tours", i.e. dialogues about food futures at the Milan universal exhibition, the Expo 2015 [Guimarães Pereira et al., 2018] the focus was on food futures and innovations.

The work carried out here is grounded in two frameworks, one that views the involvement of the citizens and other social actors in the production of knowledge as a fundamental underlying process to ensure the quality of a policy or action, according to the PNS approach. On the other hand the idea of "Futuring" as a means to think about the present is well in line with the ideas of anticipatory governance, which contrary to consequentialist approaches, invites us to think about what we want to persist, what to see transformed and how this may happen. In the remaining of this paper we will talk about Futurescape Tours, to acknowledge that diversity of contexts in which such methodology can be applied. 
In this paper we present the outcome of the project carried out at the end of 2016, within an Environmental studies course (Geomorphology and sedimentology of coastal systems) at the University of Venice, aimed at collecting scenarios of the Venetian coast's future starting from the episode of storm surge 50 years ago (Aqua Granda flood). In this activity, the students built scenarios for 2056 in order to reflect in anticipatory ways about the possible effects of sea level rise on coastal areas in Venice, based not only on scientific input but also on the conversations with the inhabitants of the barrier islands of Lido and Pellestrina. They also questioned the techno-scientific approach to environmental problems and discussed the importance of developing communication skills and mind-set from the very beginning of their educational path in order to enhance the science society interface.

The project took place in November-December 2016 and involved 14 students, aged $22-23$, in their last year of the master's degree. All students had a background in scientific subjects (environmental sciences, urban planning, engineering). At the end of the geomorphology lectures, the students followed two introductory (theoretical) seminars on Futurescape Tours and on the suggested field activities. Following the field activities there were two meetings for the organisation of the collected material and the processing of the scenarios (see Figure 1). In this activity, the students were divided into three groups and the work was done autonomously, with little guidance from the teachers.

In order to build their scenarios, students were involved in three walking tours along the barrier islands of Pellestrina and Lido, looking for traces of past, present and incipient futures about coastal management in those particular Venetian regions. During these walks, the students would use photography to record what they noticed. They were free to collect any other material or input and to interview inhabitants they met during the walks. Back at the university, they were asked to build their scenarios considering both the science learnt during the academic course and knowledge coming from those other sources.

The Tours helped students with learning how to construct future scenarios, an approach increasingly required in a society that tries to work by anticipating potential problems instead of just focusing on the mitigation of the negative effects of human projects. The approach does so by creating a space where knowledges other than techno-scientific and ideas of complexity in the form of e.g. social practices, experience, citizens' memory, oral history, values, social uncertainty, creativity can be introduced and explored.

Moreover, the Tours in Venice allowed students to share knowledge with the citizens in the barrier islands and, later at the workshop, with their colleagues through photography and oral testimony; this was an important moment for exploring desirable and undesirable futures towards the development of shared visions.

This scenario creation process builds on what Ziman [1967] defines as the "collective wisdom", but above all it allows for mobilising different types of competencies that are not typically required in the academic pathway, nor valued, such as the role of students as facilitators within the group, the communication skills, the ability to express ideas, the social skills [OECD, 2005]. 
Results \&

Discussion

The learning process

The students who participated in the Tours didn't know about the Aqua Granda before our lecture. They had already participated in geomorphological field trips, where they observed the territory to study its dynamics, developing competences for e.g. become future researchers, scholars, planners, etc. However, they had never been asked before to consider other inputs than scientific facts or to look at other knowledge to imagine Venice's future; nor had they been asked to be prepared to communicate process and results of their work to other people.

At the end of the work, three very rich future scenarios were developed and discussed among students both in the Workshop and in the academic final exam. Scenarios considered different drivers, among them: coastal erosion, dune status, the MOSE barriers project and public buildings recovery. One of the main drivers was identified as the human and social factors, important for the maintenance of the territory (see Figure 1, with one of the scenarios).

As a follow-up of the course, students produced a short video and decided to present it by organising a public event in Pellestrina and Lido inviting local policy makers.

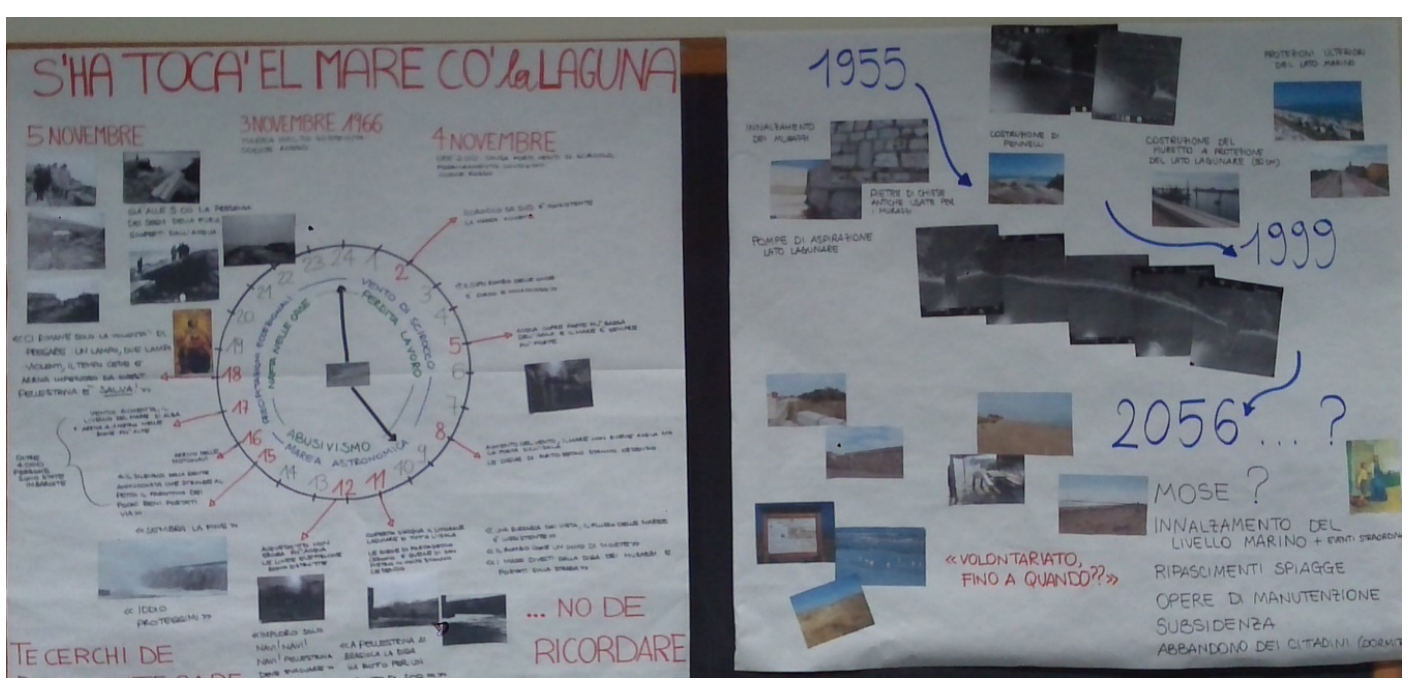

Figure 1. Example of one of the scenarios produced by the students.

The Venice Tours made students discover other aspects of that territory, in particular, its history and its transformations following events, such as the high water of 1966, or anthropic interventions, like those of the Consorzio Venezia Nuova, ${ }^{5}$ and the policies that have tried to operate to safeguard Venice, including the intervention of the MOSE. Walking and noticing along Lido and Pellestrina extended the personal and collective students' baggage mainly based on scientific issues including elements collected through the sensory experience of the places (photographs, conversations with the inhabitants of the places, audio and video annotations and other materials), which then contributed to the creation of scenarios.

\footnotetext{
${ }^{5}$ Consorzio Venezia Nuova is a private company hired by the Ministry of Infrastructure, involved in the management of the lagoon and in the planning and execution of major safeguarding works.
} 
In order to understand the reactions and opinions of students about the proposed methodology, we examined both excerpts from free conversations between students and their teacher, and results from a short survey we made at the end of the work.

Introducing the Futurescape Tours methodology to students was challenging for them and even, in some cases, disrupting. In fact, some initial comments of the students (reported below, in italics) showed a sort of resistance to our proposal, revealing students' thinking in relation to knowledge hierarchies and academic learning, privileging certain ways of knowing:

- What and why am I asked to carry out this time-consuming activity within my Geomorphology course, where I'm just supposed to learn scientific contents?

- How scientific is what I'm asked to do?

- How is it possible to produce true scenarios based on subjective observations such as photos, or on the words and experiences of the interviewed?

After the initial resistance, one can say that students appreciated the experience, which they described as very useful both for their future profession as an expert to support decisions and for the quality of teaching ("more stimulating, less theoretical and more participatory and creative"). They found interesting and unusual to be asked to interact with inhabitants about their field of study and to base their scenarios also on the input collected during interactions with them. The use of alternative tools and materials like photos or interviews with people were also very much appreciated.

Students reflected that involving the people of Pellestrina and Lido had been a valuable exercise as the local residents had "shown a strong connection to their past" and talking with them had enabled students to "catch the feelings of the local residents". Many comments highlighted the interaction with citizens as crucial to avoid future conflicts. Inhabitants are rarely asked to give opinions or contribute to the management of their territory, and this is viewed as incomprehensible because "the human element, can determine, with its behaviour, the development of alternative scenarios and therefore cannot be ignored". The students were impressed by the immense voluntary work done by the interviewees to maintain the territory; "people showed local knowledge, talked about their experience during Aqua Granda, lessons learnt and this [insights] enriched our scenario".

A sort of acknowledgement of reciprocal roles in the care for the territory also emerged: "the inhabitants of Pellestrina were curious and interested in the research conducted by us, they even opened the local museum which is closed due to lack of personnel and this motivated us to investigate aspects they had neglected". During the conversations with the inhabitants, it emerged that they feel abandoned; the two barrier islands are two different environments separated from Venice. Both the

\footnotetext{
${ }^{6}$ The sentences quoted (in italics) along this paragraph derive from the comments of the students in the questionnaires.
} 
inhabitants of Pellestrina and those of Lido are very tied to the past: "yet to save Venice means to consider the lagoon and the barriers as inhabited places; hence, saving not only the natural and ecological system and its biodiversity, but also people living there".

The experience allowed students to understand how people who live in those places perceive the past, the present, and how they project themselves into the future, providing practical solutions for land management in their daily life. Students' scenarios were built starting from the expectations and views of the inhabitants; some of them were entitled after expressions used by inhabitants during the conversations (see the title of scenario on the left in Figure 1 "s' ha tocca el mar con la laguna", the sea has touched the lagoon). Students acknowledged the opportunity to see through complexity: "this project allowed us to see the system as a whole and not only from the ecological-environmental point of view".

Few students were instead sceptical about building a scenario based on "non-scientific" knowledge such as oral testimonies or experiences from citizens: "scenarios are to be validated by scientists, otherwise they are not correct". Finally, some students observed that all this work would go beyond the syllabus and the time scheduled in an Environmental sciences course.

Final remarks

The activity described in this paper was introduced in an Environmental Science university course as a learning space about the territory, with the idea that such an approach would help students discovering matters of concern and care about the environment they study in experiential ways, as well as developing a humble attitude towards planning and governing those matters. In addition, the aim has been to learn how to anticipate contested issues, by identifying and engaging with relevant actors. The experiment was challenging to all the participants; yet Universities are privileged places where new learning practices can be explored aiming at preparing students for their roles as future researchers, scholars, planners. Actually, as shown by some surveys [Virtanen et al., 2016; Niemi and Multisilta, 2016] STEM students — both at the university and PhD level — show no passion and declare to feel extraneous to work proposed by tutors. This is partly due to the fact that they enter a traditional teaching system where there is a deep gap between the abstract knowledge to be "transferred", acquired and increasingly measured, and the practical, performative knowledge students are expected to use in their professional lives [Colucci-Gray, 2018]. Hence, in order to better respond to the global drivers for "systemic change" heralded, for example in the United Nations Sustainable Development Goals [United Nations Division for Sustainable Development Goals, 2015], more engaging practices are needed at University level that bring students to the complexity of research, planning and policy processes, especially but not only about environmental issues.

Our experience seems to suggest that introducing participatory and experiential activities where the student is at the centre of the process, could change students' attitude towards future scientific research and professional consultancy by developing skills that sustain practices inclusive of different ways of knowledge, not only the techno-scientific one. To start with the methodology applied allowed for the different types of outcomes that can affect the way students explore their territory, challenge their prejudice on knowledge hierarchies, open to different ways of investigating matters of concern and offer new opportunities of learning. 
This is also because the Tours invited the students to express themselves on the consequences of climate change within a territory that is known to them. The exploration of this issue took into consideration not only their scientific knowledge but also other elements (walking the territory, observing the change, interacting with the subjects who live in it, etc.). In this context, they could also explore tensions in their role as both practitioners and as citizens. The effect seems to be a more "dynamic response to the current context of socio-environmental transformation" [Colucci-Gray, 2018]. Finally, the Tours helped students building their own perspectives about the issues of concern in an original and creative way, taking into account the complexity of the matter dealt with.

This experience, conceived as an academic activity, has also grown as an example of integration and trans-generational communication, connecting different epistemologies, spaces and temporalities. In this context, the story of the Aqua Granda flood, emerged as a neglected and forgotten event, "silted" to the public attention. Students that engage other citizens in their studies, can be seen as a connection with the collective memory, suggesting that the making of futures cannot be done without the connections to the past and present; involving young people in the imagination of futures requires inherently the involvement of the past.

Finally, the work presented here emphasises the importance of introducing sensorial and experiential activities, such as Futurescape Tours or - Futuring Tours, - and a PNS approach in teaching environmental issues at a university course, as a way of challenging students thinking in relation to knowledge hierarchies. Furthermore, the experience suggests that teaching science with a post-normal science framing can make visible the complexity of societal issues, in other words the understanding that for many practical societal problems, one cannot rely in science alone but needs to engage other knowledges, as well.

It could be interesting to extend this approach to other environmental courses to verify the practical possibility of integrating it systematically into the academic curricula.

References

Alvarez, A. and Rogers, J. (2006). 'Going "out there": learning about sustainability in place'. International Journal of Sustainability in Higher Education 7 (2), pp. 176-188. https://doi.org/10.1108/14676370610655940.

Barth, M., Adomßent, M., Fischer, D., Richter, S. and Rieckmann, M. (2014). 'Learning to change universities from within: a service-learning perspective on promoting sustainable consumption in higher education'. Journal of Cleaner Production 62, pp. 72-81. https://doi.org/10.1016/j.jclepro.2013.04.006.

Clayton, S. and Opotow, S., eds. (2003). Identity and the natural environment. The psychological significance of nature. Cambridge, MA, U.S.A.: MIT Press.

Colucci-Gray, L. (2018). 'Complex knowing: promoting response-ability within music and science teacher education'. In: Posthumanism and higher education: reimagining pedagogy, practice and research. Ed. by C. Taylor and A. Bayley. U.K.: Palgrave.

Davies, S. R., Selin, C., Gano, G. and Guimarães Pereira, A. (2013). 'Finding futures: a spatio-visual experiment in participatory engagement'. Leonardo 46 (1), pp. 76-77. https://doi.org/10.1162/leon_a_00489. 
Funtowicz, S. and Ravetz, J. (2003). ‘Post-normal science'. In: Online Encyclopedia of Ecological Economics. International Society for Ecological Economics.

Funtowicz, S. O. and Ravetz, J. R. (1991). 'A new scientific methodology for global environmental issues'. In: Ecological economics: the science and management of sustainability. Ed. by R. Costanza. New York, U.S.A.: Columbia University Press, pp. 137-152.

Gray, D. S. and Colucci-Gray, L. (2018, accepted/in press). 'Laying down a path in walking: student teachers' emerging ecological identities'. Environmental Education Research.

Guimarães Pereira, A., L'Astorina, A., Ghezzi, A. and Tomasoni, I. (2018). Dialoghi sul cibo: Food Futuring Tours ad \#expo2015/Dialogues on food: Food Futuring Tours at the \#expo2015. EUR 28213. Luxembourg: European Commission. https://doi.org/10.2788/684250.

Guimarães Pereira, A. and Funtowicz, S. (2013). 'VISIONS for Venice in 2050: Aleph, story telling and unsolved paradoxes'. Futures 47, pp. 69-78. https://doi.org/10.1016/j.futures.2013.01.001.

L'Astorina, A. and Valente, A. (2011). 'Communicating science at school: from information to participation model'. Italian Journal of Sociology of Education 3 (3), pp. 210-220. https://doi.org/10.14658/pupj-ijse-2011-3-10.

Lisle, A. M. (2000). 'All hail reflexivity'. Annual Review of Critical Psychology 2, pp. 109-129.

Nazir, J. and Pedretti, E. (2015). 'Educators' perceptions of bringing students to environmental consciousness through engaging outdoor experiences'. Environmental Education Research 22 (2), pp. 288-304. https://doi.org/10.1080/13504622.2014.996208.

Niemi, H. and Multisilta, J. (2016). 'Digital storytelling promoting twenty-first century skills and student engagement'. Technology, Pedagogy and Education 25 (4), pp. 451-468. https://doi .org/10.1080/1475939x.2015.1074610.

Nosengo, N. (2003). 'Save our city!' Nature 424 (6949), pp. 608-609. https://doi.org/10.1038/424608a.

OECD (2005). The Definition and Selection of key Competencies (DeSeCo). Executive summary. URL: http://www.oecd.org/education/skills-beyond-s chool/definitionandselectionof competenciesdeseco.htm.

Schneidewind, U., Singer-Brodowski, M., Augenstein, K. and Stelzer, F. (2016). Pledge for a transformative science. A conceptual framework. Wuppertal Paper 191. Wuppertal, Germany: Wuppertal Inst. for Climate, Environment and Energy. URL: https://nbn-resolving org/urn:nbn: de: bsz : wup4-opus-64142.

Selin, C. and Pillen Banks, J. (2014). Futurescape city tours: a novel method for civic engagement. Tempe, AZ, U.S.A.: The Center for Nanotechnology in Society at Arizona State University (CNS-ASU).

Suman, D., Guerzoni, S. and Molinaroli, E. (2005). 'Integrated coastal management in the Venice lagoon and its watershed'. Hydrobiologia 550 (1), pp. 251-269. https://doi.org/10.1007/s10750-005-4393-x.

United Nations Division for Sustainable Development Goals (2015). Transforming our world: the 2030 Agenda for Sustainable Development. New York, U.S.A.: United Nations - Sustainable Development knowledge platform. URL: https: //sustainabledevelopment.un.org/post2015/transformingourworld (visited on July 2018). 
Virtanen, T. E., Kiuru, N., Lerkkanen, M.-K., Poikkeus, A.-M. and Kuorelahti, M. (2016). 'Assessment of student engagement among junior high school students and associations with self-esteem, burnout and academic achievement'. Journal for Educational Research Online 8 (2), pp. 136-157.

URL: http://nbn-resolving org/urn:nbn: de:0111-pedocs-124300.

Ziman, J. M. (1967). Public knowledge: an essay concerning the social dimension of science. U.K.: Cambridge University Press.

Alba L'Astorina works at the Institute for Remote Sensing of the Environment (IREA) of the Italian National Research Council (CNR), in Milano. She is member of the CNR Research Unit "Social Studies on Science, Communication and Education" whose aim is to investigate the major issues concerning the relationship between science, technology and society. Her specific topics of research are science communication; public engagement; science education, Responsible Research and Innovation. She teaches Science Communication in Theory and in Practice within various PhD courses. E-mail: lastorina.a@irea.cnr.it.

Alessia Ghezzi works at the European Commission's Joint Research Centre, researching in the field of science and technology studies. She has a master degree in archival sciences and a degree in semantic cataloguing and indexing. Her work focuses on citizen engagement and ethics evaluations in different fields. She is currently engaged in different projects focused on food.

E-mail: Alessia.ghezzi@ec.europa.eu.

Stefano Guerzoni, biologist, is senior associated scientist at the International Marine Center of Oristano. He spent most of his career at the Institute of Marine Sciences of the Italian National Research Council, studying coastal environments, rivers and lagoons. He wrote about one hundred scientific articles, plus some popular essays and two books ("The sick Lagoon" and "Atlas of the Lagoon"). Currently he is interested in science education, open science and science communication. E-mail: s.guerzoni@fondazioneimc.it.

Emanuela Molinaroli, geologist, Associate Professor at the Department of Environmental Sciences, Informatics and Statistics, University Ca' Foscari Venice. The research activity mainly concerns petrological, morphological and sedimentological studies in transitional environments. She has also worked on problems related to Saharan dust transport towards Mediterranean. She wrote more than one hundred scientific papers, a book (Atmospheric dust and Mediterranean environment - The case of Saharan dust) and some popular articles. She teaches Geomorphology and sedimentology of coastal system and other geology courses. E-mail: molinaro@unive.it.

How to cite

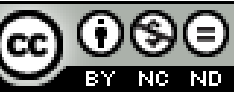

L'Astorina, A., Ghezzi, A., Guerzoni, S. and Molinaroli, E. (2018). 'Time to teach post-normal science communication? Fostering the engagement of the extended peer community in an academic course of Environmental Sciences'.

JCOM 17 (04), N02. https:/ / doi.org/10.22323/2.17040802. 